ARTICLE

https://doi.org/10.1038/s41467-019-10218-9

\title{
Metal-organic frameworks with photocatalytic bactericidal activity for integrated air cleaning
}

Ping $\mathrm{Li}^{1}$, Jiazhen $\mathrm{Li}^{1}$, Xiao Feng ${ }^{1}$, Jie $\mathrm{Li}^{1}$, Yuchen Hao ${ }^{1}$, Jinwei Zhang ${ }^{1}$, Hang Wang ${ }^{1}$, Anxiang Yin ${ }^{1}$, Junwen Zhou', Xiaojie $\mathrm{Ma}^{1} \&$ Bo Wang (i) ${ }^{1}$

Air filtration has become an essential need for passive pollution control. However, most of the commercial air purifiers rely on dense fibrous filters, which have good particulate matter (PM) removal capability but poor biocidal effect. Here we present the photocatalytic bactericidal properties of a series of metal-organic frameworks (MOFs) and their potentials in air pollution control and personal protection. Specifically, a zinc-imidazolate MOF (ZIF-8) exhibits almost complete inactivation of Escherichia coli (E. coli) (>99.9999\% inactivation efficiency) in saline within $2 \mathrm{~h}$ of simulated solar irradiation. Mechanistic studies indicate that photoelectrons trapped at $\mathrm{Zn}^{+}$centers within ZIF-8 via ligand to metal charge transfer (LMCT) are responsible for oxygen-reduction related reactive oxygen species (ROS) production, which is the dominant disinfection mechanism. Air filters fabricated from ZIF-8 show remarkable performance for integrated pollution control, with $>99.99 \%$ photocatalytic killing efficiency against airborne bacteria in 30 min and 97\% PM removal. This work may shed light on designing new porous solids with photocatalytic antibiotic capability for public health protection.

\footnotetext{
${ }^{1}$ Beijing Key Laboratory of Photoelectronic/Electrophotonic Conversion Materials, Key Laboratory of Cluster Science, Ministry of Education, School of Chemistry and Chemical Engineering, Beijing Institute of Technology, 100081 Beijing, China. Correspondence and requests for materials should be addressed to X.M. (email: xiaojiema@bit.edu.cn) or to B.W. (email: bowang@bit.edu.cn)
} 
A ir is the most critical supply for vast majority of living species on the planet and the quality of which has direct effect on human health. Due to the insufficient air exchange and increased time people spent in confined spaces, such as home, schools, offices, vehicles, and hospitals, the air contaminants are of particular concern, especially in view of their threat to vulnerable groups like children, seniors, and patients ${ }^{1-4}$. Air purifiers and fresh air ventilators are widely used air freshening equipment to regulate indoor air quality and protect people from health hazards like particulate matter (PM), bioaerosols, and volatile organic compounds (VOCs), and so on ${ }^{5,6}$. Most of these air cleaning devices are equipped with fibrous filters, which have the character of dense reticular meshwork and necessary thickness ${ }^{7,8}$. Due to the physical barrier and adhesion effect, these filters show good capture efficiency for $\mathrm{PM}^{6,9}$, meeting the high efficiency particulate air standard. But significant disadvantages exist for these commonly used fibrous filters, including high air resistance and limited inhibition ability against harmful microorganisms $s^{8,10-12}$. In particular, they are only capable of partial retention of pathogens like bacteria, fungi, and virus onto the filter surface, instead of completely cleaning them out ${ }^{11,12}$. Eventually with accumulated organic pollutants as nutrients, the filters become easy breeding ground for pathogenicity microorganism, which causes second airborne contamination ${ }^{13}$. Meanwhile, the accumulation of organism may contribute to the reduction of ventilation volume and loss of filter life. Therefore, it is highly desired to develop integrated filtration materials, which can remove PM effectively as well as interrupt transmission of germs in air by killing them completely.

The coexistence of pathogens with other pollutants (PM and VOCs, etc.) in natural air environment ${ }^{14,15}$ makes biological decontamination complicated and challenging. The routine air disinfection techniques, including chemical spraying inactivation and ultraviolet (UV) irradiation inactivation, have some prominent problems limiting their further development and practical application ${ }^{16-19}$. For instance, the extensive use of traditional chemical sanitizing agents (chlorine dioxide, ethylene oxide, etc.) is highly energy consuming and also tends to form harmful byproducts in the presence of other air contaminants ${ }^{16,20}$. UV sterilization can be an useful method ${ }^{21}$, yet it lacks of sustained effect, inevitably leads to ozone pollution, and shows low antibacterial efficiency with sunlight as light source. Alternatively, heterogeneous photocatalysis emerges to be an efficient and cost- effective approach to eliminate biological pollution ${ }^{22-25}$. The generated reactive oxygen species (ROS), such as hydroxyl radical $(\cdot \mathrm{OH})$, superoxide $\left(\cdot \mathrm{O}_{2}^{-}\right)$, singlet oxygen $\left({ }^{1} \mathrm{O}_{2}\right)$, and hydrogen peroxide $\left(\mathrm{H}_{2} \mathrm{O}_{2}\right)$, can act as strong oxidants to destroy harmful microorganisms ${ }^{24-27}$. Semiconductors like $\mathrm{ZnO}$ and $\mathrm{TiO}_{2}$ are potential photocatalysts with biocidal activity and exhibit good performance in air disinfection ${ }^{24,28}$. However, their disinfection efficiency is far from satisfactory, especially under high air flow velocity combined with other contaminants like PM and VOCs.

Metal-organic frameworks (MOFs), an emerging class of porous crystalline materials, have been vigorously investigated in the field of gas storage, separation, and catalysis ${ }^{29}$. Recently, we and others had embarked on studying possibilities of MOFs as adsorbents and catalysts for air pollution control ${ }^{30-32}$. Progress has been made for highly efficient PM removal by developing MOF-based filters (MOFilter) in our previous work ${ }^{33,34}$. Large surface area, high porosity, well-dispersed active centers, and tunable functionalities enable MOFs not only good candidates for air filtration but also promising heterogeneous photocatalysts for air pollutants oxidation ${ }^{35}$. Particularly, MOFs offer us an opportunity to optimize the photocatalytic performance at the molecular level by rationally tuning metal clusters or organic linkers ${ }^{36,37}$, which is regarded as a significant competitive advantage of MOFs over traditional semiconductors. Owing to the extraordinary designability of MOFs, successful applications have been realized in photocatalytic area like water splitting ${ }^{38}$, $\mathrm{CO}_{2}$ reduction ${ }^{39}$, ROS-dominated toxic chemicals oxidation ${ }^{40}$, and so on. We decided to explore the possibilities of MOFs for efficient light-catalyzed air sterilization. In combination with strong PM filtration capability and intriguing antimicrobial activity, we strive to develop efficient and integrated air filters based on MOFs (Fig. 1).

Herein, after careful comparison, ZIF-8 (zinc-imidazolate MOF) was selected from five typical water stable MOFs. Superior to ZIF-11 (zinc-benzimidazole MOF) and three representative MOF photocatalysts, including MIL-100(Fe), $\mathrm{NH}_{2}-\mathrm{MIL}-125(\mathrm{Ti})$, and $\mathrm{NH}_{2}$-UIO-66(Zr), ZIF-8 exhibits $>99.9999 \%$ inactivation efficiency against Escherichia coli (E. coli) in saline under $2 \mathrm{~h}$ of simulated solar irradiation. Significantly, ZIF-8 also outperforms the extensively used biocidal photocatalysts $\mathrm{ZnO}$ and anatase $\mathrm{TiO}_{2}$ in both inactivation rate and efficiency. Electron paramagnetic resonance (EPR) measurement, ROS quenching experiments combined with $\mathrm{Zn}^{2+}$ leaching, and germicidal test

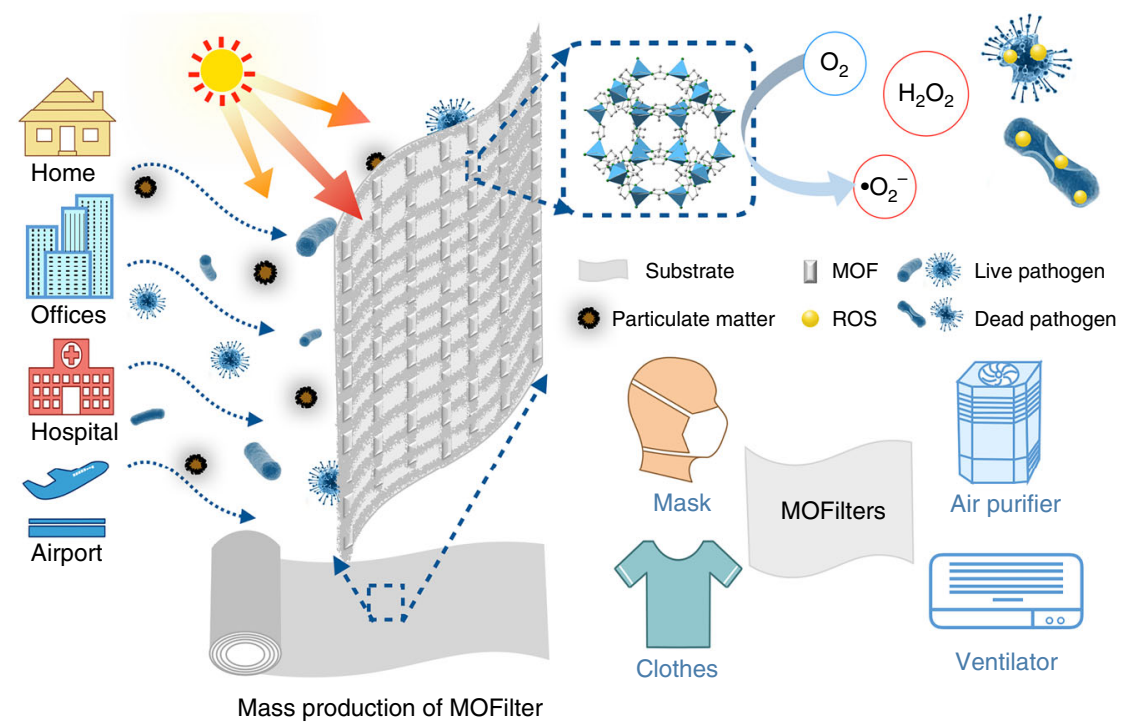

Fig. 1 Schematic of metal-organic framework (MOF)-based filter. Schematic representation of MOF-based filter (MOFilter) for integrated air cleaning 
confirm that $\mathrm{O}_{2}$ could be readily activated by photoinduced $\mathrm{Zn}^{+}$ intermediate catalytic centers within porous MOF to produce $\cdot \mathrm{O}_{2}{ }^{-}$via electron transfer, and the formation of ROS like $\cdot \mathrm{O}_{2}{ }^{-}$ and $\mathrm{H}_{2} \mathrm{O}_{2}$ is responsible for the excellent bactericidal activity of ZIF-8. Benefiting from its favorable feature, ZIF-8 was further processed as the MOFilter showing outstanding performance for integrated air pollution control and personal protection. MOFilter serves as a filtration media with $97 \%$ PM capture efficiency achieved at a flow rate of $0.7 \mathrm{~m} \mathrm{~s}^{-1}$, as well as a photoinduced contact-killing surface toward airborne bacteria with $>99.99 \%$ bactericidal efficiency realized in $30 \mathrm{~min}$. This study highlights the importance of MOFs in environmental photocatalysis, and may give new ideas for the design of porous photobactericidal materials.

\section{Results}

Photocatalytic disinfection performance of ZIF-8. We initially examined the photocatalytic antibacterial activity of five typical water stable MOFs, constructed from different metal or ligands (MIL-100(Fe), $\mathrm{NH}_{2}$-MIL-125(Ti), NH $\mathrm{N}_{2}$-UIO-66(Zr), ZIF-11(Zn), and ZIF-8(Zn)) (Supplementary Figs. 1, 2). The disinfection experiments were conducted in $0.9 \%(\mathrm{w} / \mathrm{v})$ saline with initial $E$. coli cell density at $10^{7}$ colony-forming unit $(\mathrm{CFU}) \mathrm{mL}^{-1}$ and catalyst dosage at $500 \mathrm{mg} \mathrm{L}^{-1}$. A $300 \mathrm{~W}$ Xe lamp coupled with an AM 1.5 filter $(300 \mathrm{~nm}<\lambda<1100 \mathrm{~nm})$ was employed as light source with optical power density fixed at $100 \mathrm{~mW} \mathrm{~cm}^{-2}$ (1 sun) to simulate sunlight irradiation. As shown in Fig. 2a, b, ZIF-8 exhibits almost complete inactivation of E. coli (inactivation efficiency of $>99.9999 \%$, equivalent to $\left.6.1,-\log _{10}\left(C / C_{0}\right)\right)$ after 120 min of light irradiation, whereas light alone and ZIF-8 in dark both show negligible toxic effect on E. coli over the same time period. Particularly, only $<77 \%$ inactivation efficiency $\left(0.6,-\log _{10}\right.$ $\left(C / C_{0}\right)$ efficiency) was achieved with light alone. ZIF-8 is greatly superior to MIL-100(Fe), $\mathrm{NH}_{2}$-MIL-125(Ti), and $\mathrm{NH}_{2}$-UIO-66 (Zr) in photoinduced antibacterial performance, which are three representative MOF photocatalysts exhibiting high activity in photocatalytic reactions like $\mathrm{CO}_{2}$ reduction ${ }^{35,41}$. ZIF-8 also shows much stronger photocatalytic inactivation effect on $E$. coli by comparing with ZIF-11. Encouraged by the excellent photocatalytic characteristic of ZIF-8, we further studied its antibacterial activity in detail. We found that the antibacterial efficiency was largely dependent on the dosage of ZIF- 8 . We also achieved $99.999 \%$ reduction of $E$. coli by lowering the catalyst dosage to $300 \mathrm{mg} \mathrm{L}^{-1}$ (Supplementary Fig. 3). Fluorescence assays of $E$. coli cells with different illuminating time were conducted to confirm the light-induced bacteria-killing behavior of ZIF-8 (Supplementary Fig. 4). The number of dead bacteria increased with irradiation time, and few E. coli cells survived after $120 \mathrm{~min}$. And, there was no bacteria recovery observed in the following 3 days after removing ZIF-8 and light, indicating the irreversible destruction of E. coli (Supplementary Fig. 5). Very importantly, ZIF-8 stays stable in $0.9 \%(\mathrm{w} / \mathrm{v})$ saline aqueous under $120 \mathrm{~min}$ of light illumination (Supplementary Fig. 6). Although trace leached $\mathrm{Zn}^{2+}$ ions $\left(2.65 \mathrm{mg} \mathrm{L}^{-1}\right)$ were detected by inductively coupled plasma mass spectrometry (ICP-MS), it was proved that a small amount of ZIF-8 precursors including $\mathrm{Zn}^{2+}$ and 2methylimidazole (H-MeIM) had negligible effect on bacteria reduction comparing with blank control $\left(\mathrm{Zn}^{2+}\right.$ ions at $3 \mathrm{mg} \mathrm{L}^{-1}$ gives $93.5 \%$ inactivation efficiency; $\mathrm{H}$-MeIM at $7 \mathrm{mg} \mathrm{L}^{-1}$ gives $73.7 \%$ efficiency; blank control: light irradiation without any catalyst gives $76.3 \%$ inactivation efficiency under the identical
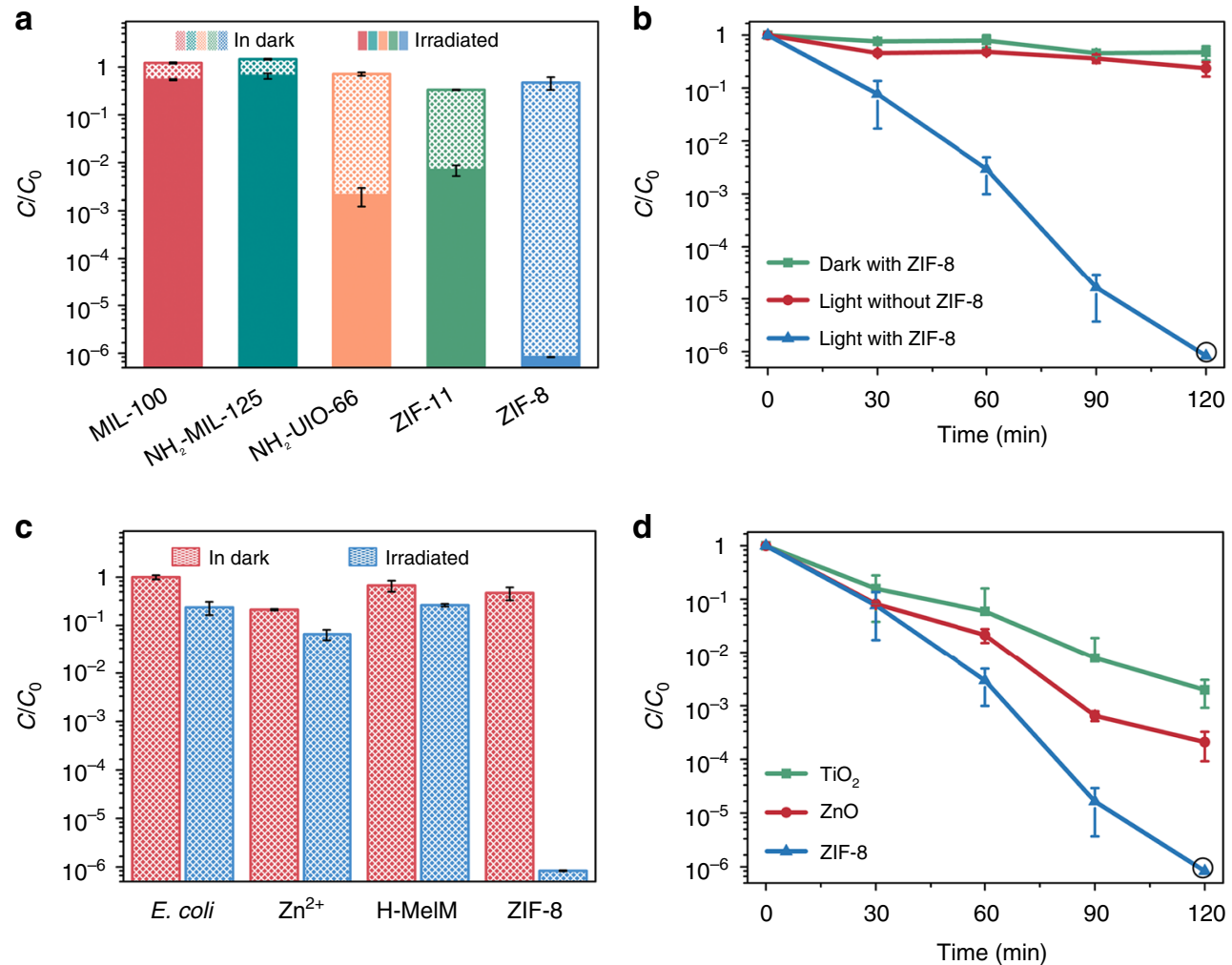

Fig. 2 Photocatalytic disinfection performance of ZIF-8 (zinc-imidazolate MOF). a Disinfection performance comparison among five metal-organic frameworks (MOFs). $\mathbf{b}$ Inactivation kinetics of $E$. coli in the presence of ZIF-8. $\mathbf{c}$ Inactivation efficiency against $E$. coli in the presence of $\mathrm{Zn}^{2+}\left(3 \mathrm{mg} \mathrm{L}^{-1}\right), 2-$ methylimidazole (H-MelM) $\left(7 \mathrm{mg} \mathrm{L}^{-1}\right)$, and $\mathrm{ZIF}-8\left(500 \mathrm{mg} \mathrm{L}^{-1}\right)$, respectively. d Disinfection performance comparison among $\mathrm{ZIF-8,} \mathrm{TiO}{ }_{2}$, and $\mathrm{ZnO}$ undersimulated solar irradiation. In the disinfection performance, the error bars are calculated via repeating the measurements for three times and the black circle represents no measurable levels of bacteria in the culture medium 
conditions) (Fig. 2c) ${ }^{42,43}$. It is noteworthy that the levels of $\mathrm{Zn}^{2+}$ released from ZIF-8 are much lower than the minimum inhibitory concentration (MIC, $31.25 \mathrm{mg} \mathrm{L}^{-1}$ ) and minimum bactericidal concentration (MBC, $250 \mathrm{mg} \mathrm{L}^{-1}$ ) (Supplementary Fig. 7 and Supplementary Table 1). This indicates that the remarkable antibacterial effect arises from the intact ZIF-8 in the presence of light irradiation. Moreover, the photocatalytic disinfection activity of ZIF-8 was evaluated by comparing with two traditional semiconductive photocatalysts, anatase $\mathrm{TiO}_{2}$ and $\mathrm{ZnO}$ (Supplementary Fig. 8). We can see that ZIF-8 is much more active than the above two materials. Over $120 \mathrm{~min}$ the log inactivation efficiency of ZIF-8 $(6 \mathrm{log})$ is three and four times higher than that of $\mathrm{ZnO}(3 \mathrm{log})$ and anatase $\mathrm{TiO}_{2}(2 \mathrm{log})$, respectively ${ }^{28,44}$ (Fig. $\left.2 \mathrm{~d}\right)$. Also, the first-order bactericidal rate of ZIF-8 $\left(0.05 \mathrm{~min}^{-1}\right)$ is faster than that of contrasting materials $\left(0.02\right.$ and $0.03 \mathrm{~min}^{-1}$ for anatase $\mathrm{TiO}_{2}$ and $\mathrm{ZnO}$, respectively) (Supplementary Fig. 9). This suggests that nanoporous structure is beneficial for the enhancement of photocatalytic activity, due to the possible shortened migration distance of photoinduced carriers from bulk to catalyst surface ${ }^{41}$.

Band-structure characterization of ZIF-8. Given the satisfactory disinfection performance of ZIF-8, its photocatalytic mechanism was further studied. First, the semiconductor properties of ZIF-8 were characterized, since the band structure can directly affect the photocatalytic disinfection efficiency and mechanism. ZIF-8 shows two absorption peaks at 227 and $350 \mathrm{~nm}$, respectively (Supplementary Fig. 10). The strong absorption centered at 227 nm could be attributed to intraligand charge transfer, and shows a slight red shift relative to H-MeIM. The broad absorption at longer wavelength of $350 \mathrm{~nm}$ is responsible for ligand to metal charge transfer (LMCT), as confirmed by the low-temperature EPR study (Fig. 3b). Accordingly, the bandgap energy was a

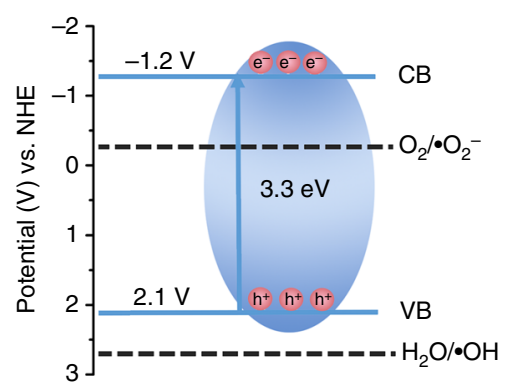

C

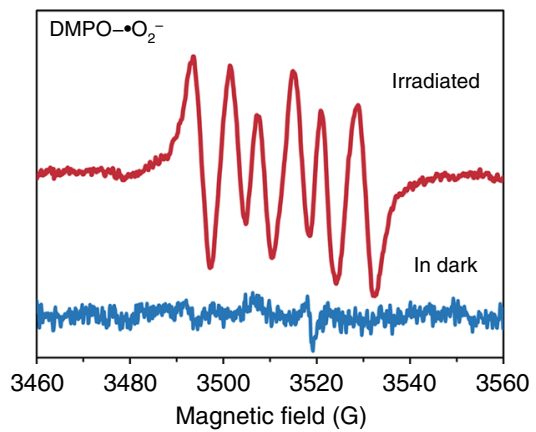

e

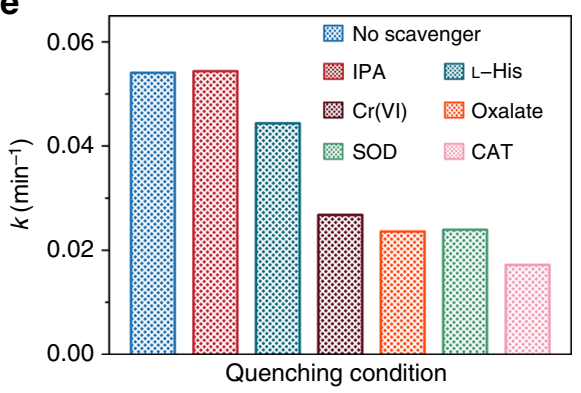

b

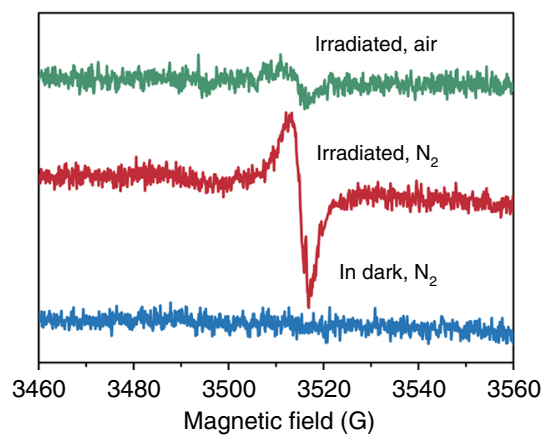

d

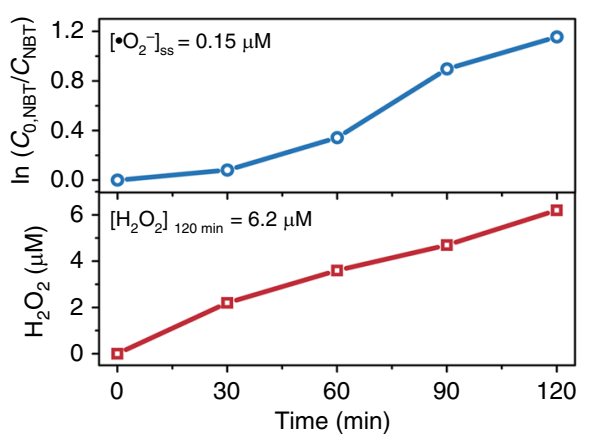

f

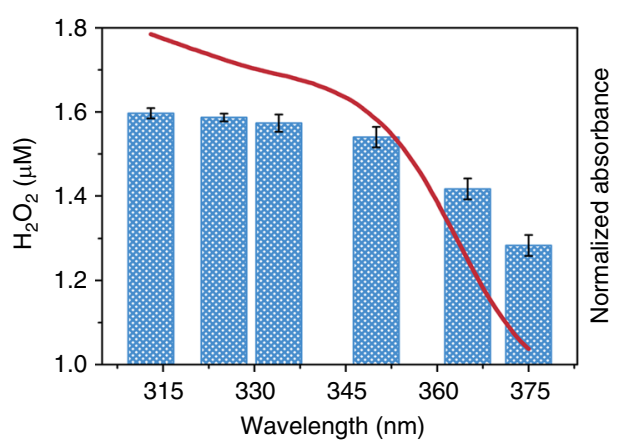

Fig. 3 Band-structure characterization and photocatalytic disinfection mechanism of ZIF-8 (zinc-imidazolate MOF). a The band positions of ZIF-8 with respect to the reactive oxygen species (ROS) formation potential. Conduction band (CB) and valence band (VB) represent conduction band and valence band respectively. $\mathbf{b}$ Electron paramagnetic resonance (EPR) spectra of ZIF-8 at $77 \mathrm{~K}$ in dark and under light irradiation $(300 \mathrm{~nm}<\lambda<1100 \mathrm{~nm})$ in different atmosphere. c EPR spectra of DMPO- $\bullet \mathrm{O}_{2}^{-}$for ZIF-8 under light irradiation and in dark. d Steady-state concentration of $\bullet \mathrm{O}_{2}{ }^{-}$calculated from the decay of nitroblue tetrazolium (NBT) and hydrogen peroxide $\left(\mathrm{H}_{2} \mathrm{O}_{2}\right)$ accumulation over time, respectively. e The first-order disinfection rate on $\mathrm{ZIF}-8$ with different scavengers (IPA $\rightarrow \bullet \mathrm{OH}$, L-His $\rightarrow{ }^{1} \mathrm{O}_{2}, \mathrm{Cr}(\mathrm{VI}) \rightarrow \mathrm{e}^{-}$, Oxalate $\rightarrow \mathrm{h}^{+}$, SOD $\rightarrow \bullet \mathrm{O}_{2}^{-}, \mathrm{CAT} \rightarrow \mathrm{H}_{2} \mathrm{O}_{2}$ ). $\mathbf{f}$ Dependence of the amount of released $\mathrm{H}_{2} \mathrm{O}_{2}$ by $\mathrm{ZIF}-8$ on the wavelength of incident light and the ultraviolet-visible (UV-vis) spectra of ZIF-8. The error bars are calculated via repeating the measurements for three times. SOD superoxide dismutase, IPA isopropanol, DMPO 5,5-diemthyl-1-pyrroline N-oxide 
estimated to be $3.3 \mathrm{eV}^{45}$. The Mott-Schottky measurements conducted at three different frequencies give the n-type semiconductor nature of ZIF-8 and the flat band position of ZIF-8 at $\sim-1.2 \mathrm{~V}$ vs. NHE, which roughly equals to the bottom of conduction band (Supplementary Fig. 11). As shown in Fig. 3a, the valence band potential is then calculated to be $2.1 \mathrm{~V}$ vs. NHE, which was further proved by valence band X-ray photoelectron spectra (VB-XPS) (Supplementary Fig. 12). The band position of ZIF-8 together with ROS reaction potential was illustrated in Fig. 3a.

Photocatalytic disinfection mechanism of ZIF-8. Upon light excitation, photoelectrons are generated via LMCT process and trapped on the surfaces of ZIF- 8 as paramagnetic $\mathrm{Zn}^{+}$sites, as supported by the obvious signal at $g=2.003$ in EPR spectra recorded at $77 \mathrm{~K}$ in nitrogen (Fig. $3 \mathrm{~b})^{46}$. When irradiation occurs in air, EPR signal is strongly attenuated, suggesting the transfer of electrons from $\mathrm{Zn}^{+}$centers to $\mathrm{O}_{2}$. Indeed, $\bullet \mathrm{O}_{2}{ }^{-}$has been detected by EPR technique using spin-trap agents (5,5-diemthyl-1-pyrroline $\mathrm{N}$-oxide (DMPO)), and also been quantified by employing nitroblue tetrazolium (NBT) reduction method ${ }^{25,27}$. As seen in Fig. 3c, six characteristic peaks for typical DMPO- $\bullet \mathrm{O}_{2}{ }^{-}$adducts were obviously observed for irradiated ZIF-8, in sharp contrast to the silent spectra for unirradiated sample. As well, insoluble blue formazan was produced with the existence of NBT, and ca. 0.15 $\mu \mathrm{M}$ of steady-state $\cdot \mathrm{O}_{2}{ }^{-}$was calculated correspondingly (Fig. $3 \mathrm{~d}$ and Supplementary Fig. 13). From Fig. 3a we can see that photoelectrons in conduction band of ZIF-8 $(-1.2 \mathrm{~V}$ vs. NHE) is negative enough to reduce the surface adsorbed $\mathrm{O}_{2}$ to $\bullet \mathrm{O}_{2}{ }^{-}$ $(-0.33 \mathrm{~V} \text { vs. NHE })^{47,48}$. But the generation of $\bullet \mathrm{OH}$ is thermodynamically unfavorable due to the deficient valence band potential of ZIF-8 (2.1 V vs. NHE) for the oxidation of water $(2.68 \mathrm{~V} \text { vs. NHE })^{47}$, which was strongly supported by the absence of DMPO-.OH EPR signal for both irradiated and unirradiated ZIF-8 (Supplementary Fig. 14). The absence of $\bullet \mathrm{OH}$ was also confirmed by using a fluorescent method with coumarin (Cou) as probe (Supplementary Fig. 15) ${ }^{49}$. The unchanged antibacterial performance of ZIF-8 in the presence of $\bullet \mathrm{OH}$ quencher further indicates the incapability of ZIF-8 for $\bullet \mathrm{OH}$ photogeneration (Fig. 3e). More importantly, by using $p$-hydroxyphenylacetic acid (HPA) as $\mathrm{H}_{2} \mathrm{O}_{2}$ probe ${ }^{27}$, we found that $\mathrm{H}_{2} \mathrm{O}_{2}$ was generated in the photocatalytic system with a total concentration of ca. $6.2 \mu \mathrm{M}$ after $120 \mathrm{~min}$ (Fig. 3d. and Supplementary Fig. 16). Its wavelength-dependent evolution trend matched well with the optical absorption of ZIF-8 (Fig. 3f and Supplementary Fig. 17). $\mathrm{H}_{2} \mathrm{O}_{2}$ was considered as the leading active species accounting for the damage of bacteria, as verified by the strongest effect of $\mathrm{H}_{2} \mathrm{O}_{2}$ in scavenger quenching experiments, along with the response of bacteria reduction and $\mathrm{H}_{2} \mathrm{O}_{2}$ level by alternating light and dark (Fig. 3e and Supplementary Figs. 18, 19). In the current system, it can be produced at the reduction site of ZIF- 8 via oxygenreduction pathway $\left(\mathrm{O}_{2}+2 \mathrm{H}^{+}+2 \mathrm{e}^{-} \rightarrow \mathrm{H}_{2} \mathrm{O}_{2},+0.695 \mathrm{~V}\right.$ vs. SHE) and the disproportionation reaction of $\bullet \mathrm{O}_{2}{ }^{-}\left(2 \cdot \mathrm{O}_{2}{ }^{-}+\mathrm{H}^{+}\right.$ $+\mathrm{H}_{2} \mathrm{O} \rightarrow \mathrm{H}_{2} \mathrm{O}_{2}+\mathrm{O}_{2}+\mathrm{OH}^{-},+1.44 \mathrm{~V}$ vs. SHE $)^{50}$. We put forward that oxygen-reduction-related $\mathrm{ROS}\left(\mathrm{H}_{2} \mathrm{O}_{2}\right.$ and $\left.\bullet \mathrm{O}_{2}{ }^{-}\right)$rather than $\mathrm{Zn}^{2+}$ ions act as primary species contributing to photocatalytic bacterial inactivation.

Air cleaning performance of MOFilter. MOFilter was obtained by coating ZIF-8 nanocrystals via hot pressing of ZIF-8 precursors $\left(\mathrm{Zn}(\mathrm{OAc})_{2} \cdot 2 \mathrm{H}_{2} \mathrm{O}\right.$ and $\left.\mathrm{H}-\mathrm{MeIM}\right)$ and polyethylene glycol (PEG) on non-woven fabrics (NWFs) at $100^{\circ} \mathrm{C}^{51}$. As evidenced by X-ray diffraction (XRD), scanning electron microscopy (SEM), and elemental mapping, ZIF-8 nanoparticles with well-defined rhombic dodecahedral shape and an average size of $80 \mathrm{~nm}$ were successfully generated and densely layered on the fibers of NWF (Fig. 4a, b and Supplementary Fig. 20). The MOF coatings show strong affinity to the substrate ${ }^{34}$, as verified by bending and rubbing test (Supplementary Table 2 and Supplementary Fig. 21). And, $0.15 \mathrm{mg} \mathrm{cm}^{-2}$ of ZIF-8 loading was confirmed by analyzing the weight increasement of substrates. The antimicrobial activity of MOFilter was challenged by exposing to E. coli suspension. Not surprisingly, MOFilter was endowed with contact-killing behavior, and had no measurable levels of adhered E. coli cells after $1 \mathrm{~h}$ of light exposure (Supplementary Fig. 22). These favorable results encouraged us to explore the applicability of MOFilter in various scenarios. First, large-scale production of MOFilter has been achieved to meet the basic need of practical applications (Supplementary Fig. 23). Then, we demonstrated the effectiveness and flexibility of MOFilter for comprehensive decontamination of air in confined environment. As illustrated in Fig. 4c and Supplementary Fig. 24, after introducing PM or bioaerosols into the inlet section divided from a chamber by MOFilter, residual PM or survived bacteria were counted by exposing collectors to the exhaust gas. As shown in Fig. 4d, MOFilter achieved 96.8\% removal of $\mathrm{PM}_{2.5}$ particles and $97.7 \%$ removal of $\mathrm{PM}_{10}$ particles with a low pressure drop $(64 \mathrm{~Pa})$ at flow rate of $0.7 \mathrm{~m} \mathrm{~s}^{-1}$, which was as good as the performance we presented detailly in our previous work ${ }^{10,34}$. Here we focused more on the air sterilization performance of MOFilter. Model aerosols nebulized from $10^{5}$ $\mathrm{CFU} \mathrm{mL} \mathrm{mL}^{-1}$ of $E$. coli suspension were injected into the inlet section at flow rate of $0.3 \mathrm{~mL} \mathrm{~min}^{-1}$ for $1 \mathrm{~min}$. Noticeably, MOFilter shows highly efficient photocatalytic killing properties for $E$. coli dispersed in air, with bactericidal efficiency reaching to $>99.99 \%$ over $30 \mathrm{~min}$. That is quite distinct from the rather poor antibacterial ability of light-illuminated NWF $(<89 \%$ inactivation efficiency) in control experiments. It can be seen that significant bacterial contamination occurs in the outlet section of the chamber with MOFilter in dark as gas filter (Fig. 4e). This reveals the non-toxicity of MOFilter itself against $E$. coli, and also reflects the negligible retention of bacteria on MOFilter. Furthermore, in nutrient broth liquid medium we incubated five pieces of MOFilter and NWF used in the above experiment, respectively (Supplementary Fig. 25). The nutrient broth medium with lighttreated NWF immersed became very turbid due to the massive growth of E. coli, whereas that with light-treated MOFilter immersed was still clear with no bacteria recovery. The resulting phenomenon strongly supports that the excellent air sterilization performance of MOFilter arises from the photocatalytic bacteriakilling activity and not the physical barrier and adhesion effect. MOFilter still keeps sufficient activity after it has been continuously used for several times (Fig. 4f). MOFilter can be a promising candidate for comprehensive and deep purification of air in confined environment like home, schools, vehicles, etc.

Antibacterial performance of MOFilter mask. As a proof of concept, we also demonstrated the application potential of MOFilter in basic personal protective equipment like mask. MOFilter mask is a trilaminar mask with MOFilter serving as an inner biocidal layer sandwiched between two layers of NWF. The self-cleaning performance of MOFilter mask was assessed by comparison with that of commercial mask (N95). As demonstrated in Fig. 5a, the top layer of the mask was exposed to artificial pathogenic aerosols generated from E. coli suspensions for $5 \mathrm{~min}$. We can see that, under $30 \mathrm{~min}$ of simulated sunlight illumination, the number of viable bacterial cells dropped significantly with almost no measurable levels of living bacteria survived on each layer of MOFilter mask (Fig. 5b), especially the bottom layer. This result is very favorable because the bottom layer has a direct contact with human skin. On the contrary, only 


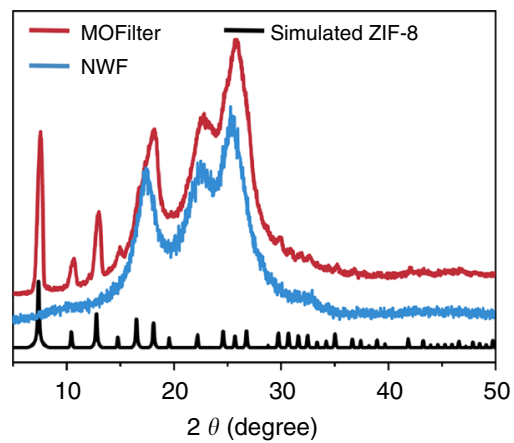

C

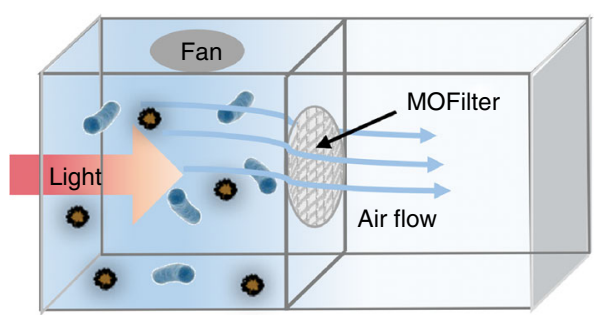

e

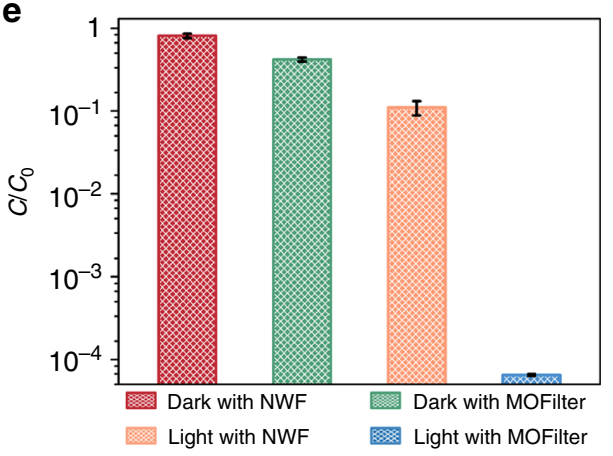

b

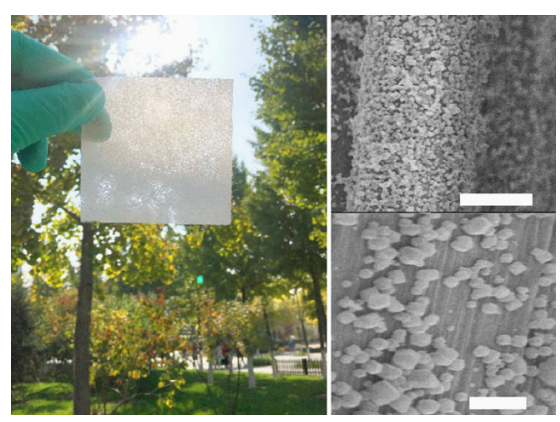

d

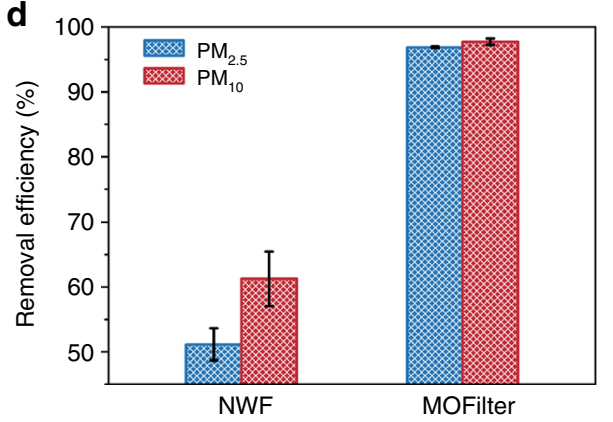

f

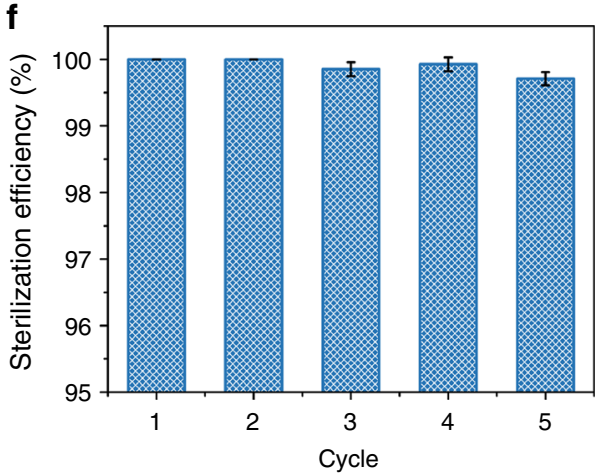

Fig. 4 Characterization of metal-organic framework (MOF)-based filter (MOFilter) and its air cleaning performance. a X-ray diffraction (XRD) patterns of non-woven fabric (NWF) and MOFilter. b Optical photo and scanning electron microscopy (SEM) images of MOFilter (scale bar, $5 \mu \mathrm{m}$ (top); $1 \mu \mathrm{m}$ (bottom)). c Schematic representation of the air cleaning system. $\mathbf{d}$ Comparison of the particulate matter (PM) filtration efficiency between MOFilter and NWF. e Comparison of the air disinfection performance between MOFilter and NWF under light and dark conditions, respectively. $\mathbf{f}$ Air disinfection performance of MOFiter continuously used for five cycles. The error bars are calculated via repeating the measurements for three times

a small number of bacteria on top cover of commercial mask was killed under light in control experiment. Significant number of bacteria flourished on N95 (Fig. 5b, c). Obviously, MOFilter mask is much more effective than commercial one in pathogens prevention. Likewise, ZIF-8-based silk clothing also presents satisfactory antibacterial effect under light illumination (Supplementary Fig. 26). The remarkable bactericidal activity indicates the great protective coating application foreground of MOF.

\section{Discussion}

In summary, we explore the photocatalytic disinfection activity of ZIF-8 and its potential use in air purification. The chargetrapping centers $\mathrm{Zn}^{+}$can be photogenerated on MOF surface via LMCT, and effectively active $\mathrm{O}_{2}$ to form $\bullet_{2} \mathrm{O}^{-}$and related ROS like $\mathrm{H}_{2} \mathrm{O}_{2}$. The ROS production rather than $\mathrm{Zn}^{2+}$ releasing mainly contributes to the biocidal properties of ZIF-8. ZIF-8 shows excellent photocatalytic antibacterial behavior, which is well beyond the performance of traditional semiconductors like $\mathrm{ZnO}$ and $\mathrm{TiO}_{2}$. Furthermore, ZIF- 8 is processed as filters with the combination of PM filtration and bacteria-killing function. We demonstrate that ZIF-8-based filter could be a kind of strong and comprehensive protection against air hazards including PM and pathogens aerosols. This study provides valuable insights for development of porous photocatalytic antibacterial materials and also open the door for the application of these materials in air disinfection.

\section{Methods}

Material characterization. Powder X-ray diffraction (XRD) patterns of the samples were measured by a Bruker Focus D8 diffractometer operating at $40 \mathrm{kV}$ voltage and $50 \mathrm{~mA}$ current with $\mathrm{Cu}-\mathrm{Ka} \mathrm{X}$-ray radiation $(\lambda=0.154056 \mathrm{~nm})$. Concentrations of $\mathrm{Zn}^{2+}$ were determined by ICP-MS with Agilent 7700 spectrometer. Low-temperature EPR measurements were performed on a BrukerA300 spectrometer operating at an X-band frequency of $9.85 \mathrm{GHz}$. All spectra were acquired at $77 \mathrm{~K}$. EPR signals of spin-trapped paramagnetic species with DMPO were recorded with a Bruker E500 spectrometer. UV-vis spectra were recorded on a UV-2600 spectrometer (SHIMADZU). The Fourier-transform infrared spectroscopy (FT-IR) spectra were recorded in the range $400-4000 \mathrm{~cm}^{-1}$ on Nicolet 170 SXFT/IR spectrometer. The thermogravimetric analysis (TG) was carried out using a TA Instruments STA449F5 apparatus in the temperature range of $35-800^{\circ} \mathrm{C}$ under $\mathrm{N}_{2}$ flow at a heating rate of $10^{\circ} \mathrm{C} \mathrm{min}^{-1} . \mathrm{N}_{2}$ sorption tests were measured using a Builder SSA-4200 automatic volumetric gas adsorption analyzer. Field-emission SEM was performed on a JEOL model JSM-7500 F with an accelerating voltage of 
a

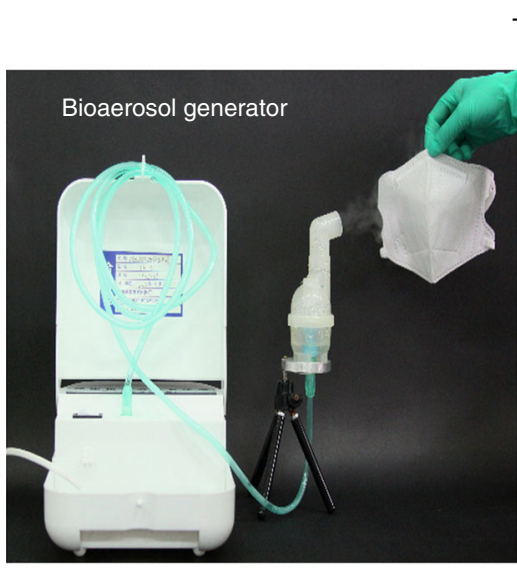

Top layer

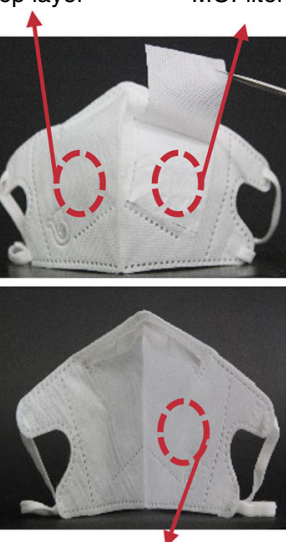

Bottom layer

C
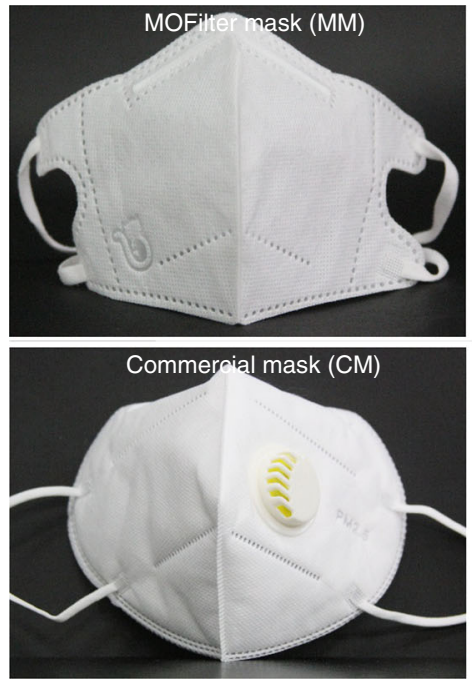
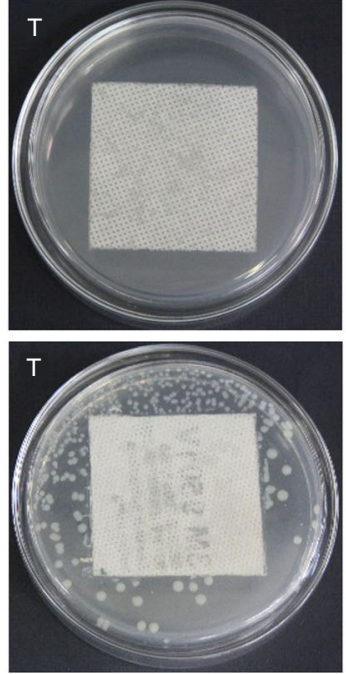

b
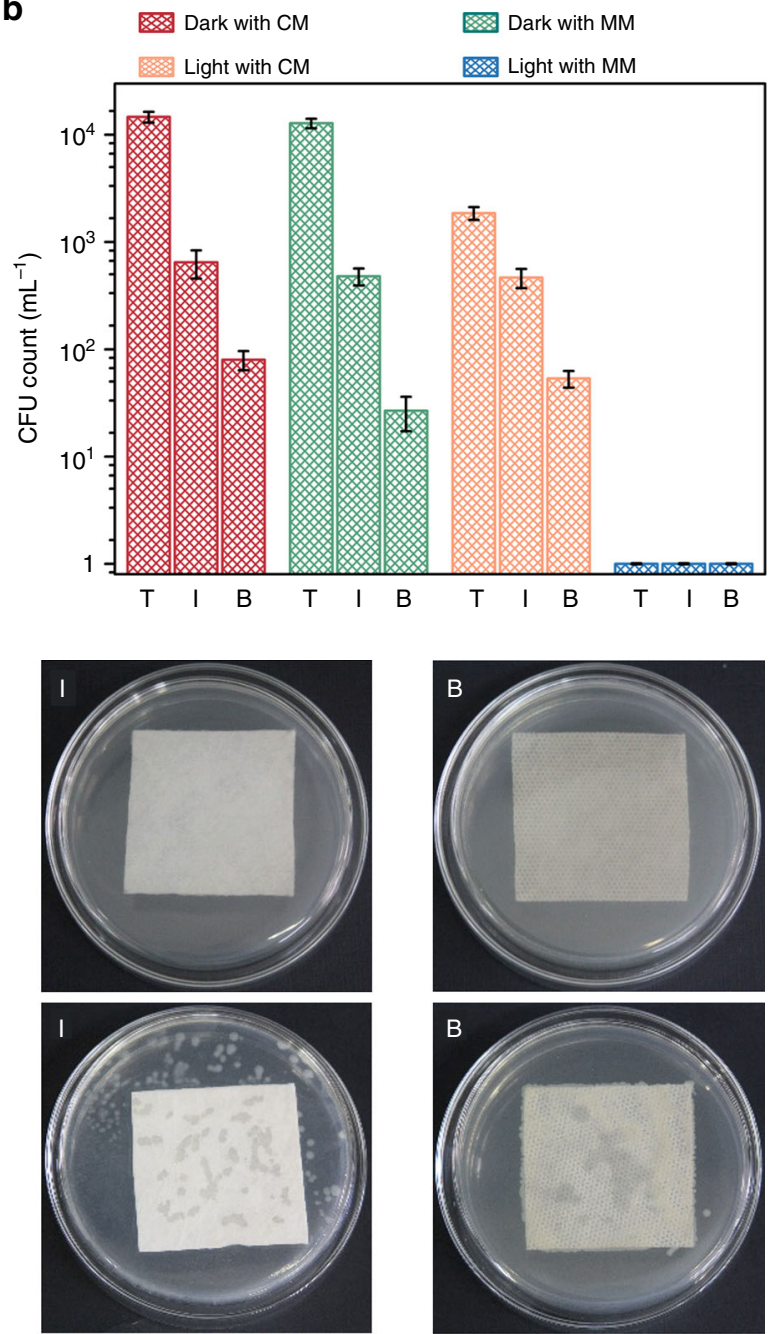
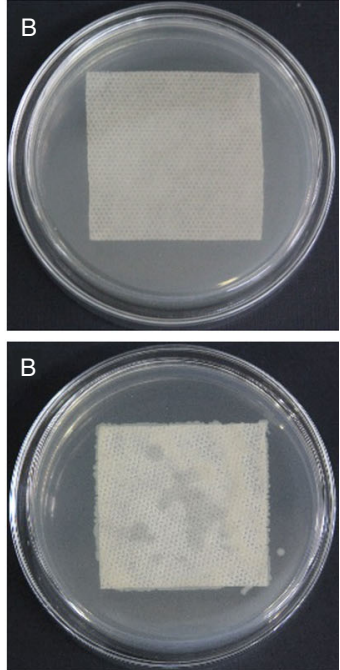

Fig. 5 Antibacterial performance comparison between metal-organic framework (MOF)-based filter (MOFilter) mask (MM) and commercial mask (CM). a Bioaerosol generation apparatus and optical images of trilaminar MOFilter mask. b, c Escherichia coli levels residual on top, inner and bottom layers of MM and CM, respectively, after 30 min of light irradiation. The number of viable cells in $\mathbf{b}$ is determined from saline eluent used for collecting living bacteria on each layer of mask after reaction. The bacterial colonies residual on eluent-treated mask are shown in $\mathbf{c}$. The top, inner, and bottom layers are denoted as $\mathrm{T}$, I and B, respectively. The error bars are calculated via repeating the measurements for three times

$5.0 \mathrm{kV}$ and a current of $10 \mathrm{~mA}$. Transmission electron microscopy (TEM) was carried out by a JEOL JEM-1200EX microscope. Fluorescence images of bacterial cells stained with N01 dye and PI dye were captured by Olympus FV1000 confocal fluorescence microscope. VB-XPS was performed on a Thermo Fisher ESCALAB 250Xi using a monochromatic $\mathrm{Al} \mathrm{Ka} \mathrm{X-ray} \mathrm{source.} \mathrm{Mott-Schottky} \mathrm{measurements}$ were performed in $0.5 \mathrm{M} \mathrm{Na}_{2} \mathrm{SO}_{4}$ solution by using a $\mathrm{CHI} 760 \mathrm{E}$ electrochemical workstation (Shanghai, China) with a standard three-electrode cell. The working electrodes were prepared as follows: the as-prepared photocatalyst $(7 \mathrm{mg})$ was ultrasonically dispersed in $0.5 \%$ Nafion solution $(0.5 \mathrm{~mL})$ to produce a slurry and then dip-coated onto a FTO glass electrode $\left(2 \times 0.5 \mathrm{~cm}^{2}\right)$. Pt plate and $\mathrm{Ag} / \mathrm{AgCl}$ electrode were used as counter electrode and reference electrode, respectively.

Synthesis of MIL-100(Fe). One point one hundred and ninety nine grams of $\mathrm{Fe}$ $\left(\mathrm{NO}_{3}\right)_{3} \cdot 9 \mathrm{H}_{2} \mathrm{O}, 0.4129 \mathrm{~g}$ of trimethyl 1,3,5-benzenetricarboxylate (BTC), $0.2976 \mathrm{~mL}$ of hydrogen fluoride solution ( $40 \mathrm{wt} \%$ ), and $15 \mathrm{~mL}$ of $\mathrm{H}_{2} \mathrm{O}$ were put into a $20 \mathrm{~mL}$ Teflon-lined autoclave and heated at $150{ }^{\circ} \mathrm{C}$ for $84 \mathrm{~h}$. After cooling the mixture to room temperature, the orange crystals were centrifuged. A treatment in hot deionized water $\left(80^{\circ} \mathrm{C}\right)$ for $3 \mathrm{~h}$ and followed by hot ethanol $\left(60^{\circ} \mathrm{C}\right)$ for $1 \mathrm{~h}$ was applied to decrease the amount of residual BTC. The final products were washed with ethanol and dried vacuum at $80^{\circ} \mathrm{C}$ for $24 \mathrm{~h}^{52}$.

Synthesis of $\mathbf{N H}_{\mathbf{2}}$-MIL-125(Ti). 2-Amino-1, 4-benzenedicarboxylic acid $\left(\mathrm{NH}_{2}-\right.$ $\mathrm{BDC}$ ) and $p$-toluylic acid (p-TA) with a molar ratio of 1:4 were chosen as organic linkers, and dissolved into a dimethylformamide (DMF)-methanol mixed solvent $(\mathrm{v}(\mathrm{DMF}) / \mathrm{v}($ methanol $)=9: 1)$. Next, titanium isopropoxide (TPOP) was added into the above solution and stirred for several minutes, the molar ratios of TPOP and
$\mathrm{NH}_{2}-\mathrm{BDC}$ is 2:3.1. Then, the reactant mixtures were moved to a $100 \mathrm{~mL}$ Teflonlined steel autoclave, sealed, and placed in an oven at $150^{\circ} \mathrm{C}$ for $24 \mathrm{~h}$ under static conditions. After that, the product was washed for several times with DMF and methanol separately to remove the remaining reactants after cooling. Then, the samples were dried overnight in a vacuum oven at $60^{\circ} \mathrm{C}^{53}$

Synthesis of $\mathbf{N H}_{\mathbf{2}}$-UiO-66. $\mathrm{ZrCl}_{4}$ (pre-dissolved in a $\mathrm{DMF} / \mathrm{HCl}$ mixture of $\mathrm{v}$ $(\mathrm{DMF}) / \mathrm{v}(\mathrm{HCl})=5: 1)$ and 2-amino-1, 4-benzenedicarboxylic acid (pre-dissolved in DMF) at a molar ratio of 1:1.4 were mixed and heated at $80^{\circ} \mathrm{C}$ overnight. The obtained powders were isolated by centrifugation and washed with DMF $(3 \times$ $30 \mathrm{~mL}$ ). Then, the powders were immersed in ethanol for 3 days (the solvent was replaced with fresh ethanol each day). Finally, the product was dried under vacuum at $150{ }^{\circ} \mathrm{C}$ overnight ${ }^{54}$.

Synthesis of ZIF-11. A solid mixture of $\mathrm{Zn}\left(\mathrm{NO}_{3}\right)_{2} \cdot 4 \mathrm{H}_{2} \mathrm{O}(0.60 \mathrm{~g})$ and benzimidazole (H-PhIM) (4.2 g) was dissolved in $360 \mathrm{~mL}$ diethylformamide (DEF) in a $500 \mathrm{~mL}$ wide-mouth glass jar. The capped jar was heated for 4 days in an isothermal oven at $100{ }^{\circ} \mathrm{C}$. The jar was then removed from the oven, and allowed to cool to room temperature naturally. The powder and mother liquor were removed by repeating the cycle of decanting, washing with DMF, sonicating several times, and dried in the vacuum oven at $120^{\circ} \mathrm{C}$ for $12 \mathrm{~h}^{55}$.

Synthesis of ZIF-8. One point two hundred and ninety one grams of $\mathrm{Zn}$ $\left(\mathrm{NO}_{3}\right)_{2} \cdot 4 \mathrm{H}_{2} \mathrm{O}$ was dissolved in $100 \mathrm{~mL}$ of methanol, and $1.621 \mathrm{~g}$ of 2 - $\mathrm{H}-\mathrm{MeIM}$ was dissolved in $100 \mathrm{~mL}$ of methanol, respectively. Then, the two solutions were mixed 
under stirring and kept statically at room temperature for $24 \mathrm{~h}$. The resultant powders were collected by centrifugation and thoroughly washed with methanol. The product was dried at $120^{\circ} \mathrm{C}$ for $12 \mathrm{~h}$ in a vacuum oven ${ }^{56}$. Highly crystalized and phase pure ZIF- 8 particles have been prepared as confirmed by PXRD results (Supplementary Fig. 1). ZIF-8 particles were also characterized by FT-IR, TG, TEM, SEM, elemental mapping, and Brunauer-Emmett-Teller (BET) adsorption (Supplementary Fig. 2). The as-obtained ZIF-8 nanocrystals show typical rhombic dodecahedron morphology, and have a high BET specific surface area of $1538 \mathrm{~m}^{2} \mathrm{~g}^{-1}$. The particle size of ZIF-8 ranges from 70 to $110 \mathrm{~nm}$, and an average diameter of $92 \mathrm{~nm}$ was obtained by statistical evaluation of 100 objects.

Fabrication of MOFilter. Four grams of zinc acetate dihydrate $(0.02 \mathrm{~mol}), 10 \mathrm{~g}$ of 2 -H-MeIM $(0.12 \mathrm{~mol})$, and $2 \mathrm{~mL}$ of PEG $(\mathrm{Mn}=200)$ were manually ground and mixed. The mixture was then loaded on substrate (the substrate is NWFs, unless otherwise specified), packed with aluminum foil, and heated with electric heating plate at $100^{\circ} \mathrm{C}$ for $2 \mathrm{~min}$. After peeling off the aluminum foil, the slice was fully washed with ethanol, dried at $80^{\circ} \mathrm{C}$ for $30 \mathrm{~min}$ and activated at $120^{\circ} \mathrm{C}$ for $6 \mathrm{~h}$ prior to use as MOFilter ${ }^{34}$.

Photocatalytic disinfection activity of MOFs in solution. Gram-negative E. coli was used as model bacteria. All disks and materials were sterilized in an autoclave before experiments. The bacterial cells were grown in nutrient broth at $37^{\circ} \mathrm{C}$ for 18 $\mathrm{h}$ to yield a cell count of approximately $10^{9} \mathrm{CFU} \mathrm{mL}{ }^{-1}$. Then, bacterial cells were collected by centrifugation (5000 rpm for $10 \mathrm{~min}$ ) and resuspended in sterile saline solution $(0.9 \%(\mathrm{w} / \mathrm{v}))$. The bacteria concentration for bactericidal study was $10^{7}$ $\mathrm{CFU} \mathrm{mL}{ }^{-1}$, which was adjusted by gradient dilution method using $0.9 \%(\mathrm{w} / \mathrm{v})$ saline solution.

Typically, $5 \mathrm{mg}$ of catalyst was added to a $50 \mathrm{~mL}$ photoreactor containing $10 \mathrm{~mL}$ of bacteria solution $\left(10^{7} \mathrm{CFU} \mathrm{mL}{ }^{-1}\right)$. The bacteria and photocatalyst were mixed by using a magnetic stirrer at room temperature, and simultaneously irradiated by simulated sunlight ( $300 \mathrm{~W}$ Xe lamp coupled with an AM 1.5 filter) for $120 \mathrm{~min}$ at the density of $100 \mathrm{~mW} \mathrm{~cm}^{-2}$. As the reaction proceeded, the mixture was carefully pipetted out at a scheduled interval and the residual bacteria concentrations were determined by the standard plate count method. The plates were incubated at $37^{\circ} \mathrm{C}$ for $20 \mathrm{~h}$. The number of colonies was enumerated through visual inspection. There were a series of experiments conducted in the dark at the same situations as the dark controls. The light control group was carried out in the absence of photocatalyst.

Regrowth test. After photocatalytic disinfection experiment, the reaction solution of ZIF-8 was stirred in dark at slow rate of $200 \mathrm{rpm}$ at $10 \mathrm{~min}, 24 \mathrm{~h}$, and $48 \mathrm{~h}$, respectively. Then, $400 \mu \mathrm{L}$ of the solution at different time intervals was added to $3.6 \mathrm{~mL}$ of nutrient broth liquid medium and the mixture was incubated at $37^{\circ} \mathrm{C}$ for $20 \mathrm{~h}$ in a shaker. The optical density at $600 \mathrm{~nm}$ was monitored every $6 \mathrm{~h}$.

Antibacterial activity of $\mathbf{Z n}^{\mathbf{2}+}$. The MIC and MBC methods were applied to assess the antibacterial activity of $\mathrm{Zn}^{2+}$. In MIC test, the serial $\mathrm{Zn}^{2+}$ solutions with different concentrations were dispersed in sterilized tubes with $2 \mathrm{~mL}$ broth media by a two-fold serial dilution method. Then, $20 \mu \mathrm{L}$ bacteria suspensions $\left(10^{7} \mathrm{CFU}\right.$ $\mathrm{mL}^{-1}$ ) were added into the serial tubes, respectively. Finally, the tubes were incubated at $37^{\circ} \mathrm{C}$ for $20 \mathrm{~h}$ and the lowest concentration of samples that inhibited visible growth of bacteria by turbidimetric method were signed as the MIC value.

$\mathrm{MBC}$ is defined as the minimum concentration of the sample required to kill 99.9\% bacteria after a defined period of incubation. In MBC test, the nutrient agar was spread onto a Petri plate, and then the invisible bacterial suspensions with different concentrations of samples taken out from the tubes were coated on the agar plates. Final agar plates with bacterial suspension were incubated at $37^{\circ} \mathrm{C}$ for $20 \mathrm{~h}$. The number of survival colonies was counted to get the MBC of $\mathrm{Zn}^{2+}$.

Photocatalytic disinfection activity of MOFilter. The photocatalytic measurements were conducted according to Chinese standard GB/T 30706-2014 procedure with a slight modification. Two milliliters of bacteria suspension $\left(10^{7} \mathrm{CFU} \mathrm{mL} \mathrm{m}^{-1}\right)$ was dropped on MOFilter surface gradually, and then irradiated by simulated sunlight for $1 \mathrm{~h}$ at the density of $100 \mathrm{~mW} \mathrm{~cm}^{-2}$. After photocatalytic disinfection reaction, MOFilter was fully washed with $20 \mathrm{~mL}$ of $0.9 \%(\mathrm{w} / \mathrm{v})$ saline solution and the resultant eluant was dispersed in sterilized tubes with $2 \mathrm{~mL}$ saline solution by a two-fold serial dilution method. Then, the samples $(50 \mu \mathrm{L})$ were plated on nutrient agar culture medium. These plates were incubated at $37^{\circ} \mathrm{C}$ for $20 \mathrm{~h}$. Then, the viable cell count was performed to obtain the results for disinfection. Also, MOFilter freshly washed by eluant was cultured in nutrient agar for $20 \mathrm{~h}$ at $37^{\circ} \mathrm{C}$ for residual analysis of adhered viable cells. There were a series of experiments conducted in the dark at the same situations described above. The light control group was carried out in the absence of photocatalyst. All the experiments were repeated for three times.

Photocatalytic air disinfection. A rectangular chamber with a cross-section of $30 \times 30 \mathrm{~cm}^{2}$ (height $\times$ width) and a length of $60 \mathrm{~cm}$ was assumed to be air duct model, which is divided into an inlet section, a reaction section, and an outlet section by MOFilter with $8 \mathrm{~cm}$ long and $8 \mathrm{~cm}$ wide. The whole device was located in a class II microbiological safety cabinet to ensure sterility of the experiments. Escherichia coli-containing aerosols with particle diameter from 1 to $5 \mu \mathrm{m}$, which was of a similar size to aerosols generated by a human sneezing or coughing, were prepared as model aerosols by nebulizing $10^{5} \mathrm{CFU} \mathrm{mL}^{-1}$ of E. coli suspension was sprayed into the reaction section at the flow rate of $0.3 \mathrm{~mL} \mathrm{~min}^{-1}$ for $1 \mathrm{~min}$. MOFilter was exposed to them under simulate sunlight illumination for $30 \mathrm{~min}$ and then air in the reaction section was sampled at a flow rate of $28.3 \mathrm{~L} \mathrm{~min}^{-1}$ with an air impactor through six 400-hole sieved head plates and over $90 \mathrm{~mm}$ Petri dishes. The sampling volume was adjusted to $28.3 \mathrm{~L}$ to avoid plate saturation. The petri dishes attached to the sampler heads contained growth medium for bacteria. Bacterial samples were collected using nutrient agar and incubated at $37^{\circ} \mathrm{C}$ for $20 \mathrm{~h}$. Every test was repeated three times. After incubation, the colonies were counted. The photocatalytic air disinfection activity of NWFs was evaluated under the same conditions described above by replacing MOFilter with NWF. The concentration of microorganisms in the air, expressed in $\mathrm{CFU} \mathrm{m}^{-3}$, was calculated using the following Eq. (1):

$$
[\text { bioaerosol }]=\frac{N}{F t},
$$

where " $F$ " and " $t$ " are the flow rate and the sampling time, respectively, and " $N$ " is the colony counts after positive hole correction.

The air disinfection efficiency of MOFilter was calculated according to the following Eq. (2):

$$
\text { Efficiency }=\frac{\left(\mathrm{C}_{0}-\mathrm{C}\right)}{\mathrm{C}_{0}},
$$

where " $C_{0}$ " $\left(\mathrm{CFU} \mathrm{m}{ }^{-3}\right)$ represents the bacterial concentration dispersed in air of reaction section after introducing E. coli-containing aerosols immediately.

PM removal experiment. PM removal test followed the method previously reported by our group. A piece of filter with a diameter of $4 \mathrm{~cm}$ was set at one side of the pipe, and an electric fan was put on the other side to help the air pass through the filter at a constant velocity $\left(0.7 \mathrm{~m} \mathrm{~s}^{-1}\right)$ measured by an anemograph (EDKORS, FS-801). The filtered air was collected in a plastic bag, and a particle counter was used to detect the PM mass concentrations with and without the filter The detection was finished before the plastic bag reached its maximum volume, and this constant pressure process ensured that the concentration of PM remained unchanged during collection. Twenty groups of mass concentration data were collected to give the average concentration. All the PM removal tests were conducted in triplicate. The PM removal efficiency of the MOFilter was calculated with the following Eq. (3):

$$
\text { Efficiency }=\frac{\left(\mathrm{C}_{0}-\mathrm{C}\right)}{\mathrm{C}_{0}},
$$

where " $C_{0}$ " $\left(\mu \mathrm{g} \mathrm{m}^{-3}\right)$ and " $C$ " $\left(\mu \mathrm{g} \mathrm{m} \mathrm{m}^{-3}\right)$ are the mass concentrations of particle matter tested with and without the filter.

Photocatalytic antibacterial activity of MOFilter mask. Escherichia coli-containing aerosols with the diameter of $1-5 \mu \mathrm{m}$ generated from $10^{6} \mathrm{CFU} \mathrm{mL}{ }^{-1}$ of bacteria suspension were prepared as model-infected aerosols. The top layer of MOFilter mask was exposed to a $0.3 \mathrm{~mL} \mathrm{~min}-1$ of aerosols flow for $5 \mathrm{~min}$ and then irradiated by simulated sunlight for $30 \mathrm{~min}$ at the density of $100 \mathrm{~mW} \mathrm{~cm}{ }^{-2}$. After that, each layer of MOFilter mask was fully washed with $20 \mathrm{~mL} 0.9 \%$ (w/v) saline solution, respectively. The concentrations of bacteria in eluant were determined by the standard plate count method. Also, each layer of mask freshly washed by eluant was incubated in nutrient agar for $20 \mathrm{~h}$ at $37^{\circ} \mathrm{C}$ for residual analysis of adhered viable cells. There were a series of experiments conducted in the dark at the same situations described above. The antibacterial performance of commercial mask was assessed under the same conditions described above. All the experiments were repeated for three times.

Empirical disinfection kinetics. The kinetics of photocatalytic bacterial inactivation are usually described using empirical equations. The Chick-Watson equation is the classical model for microorganism inactivation with a constant concentration of disinfecting agent, as expressed by following Eq. (4):

$$
\lg \left(\frac{C}{C_{0}}\right)=-k[\chi]^{n} t
$$

where " $C_{0}$ " and " $C$ " are the initial and subsequent bacterial concentrations, respectively, at the beginning of the process and after time ' $t$ ' respectively, " $k$ " is the disinfection kinetic constant, " $\chi$ " is the concentration of disinfecting agent (photocatalyst in this case), and " $n$ " is the order of reaction.

Fluorescent-based cell live/dead test. The cell membrane damage of the bacterial cells was determined with fluorescence microscope. One milliliter of bacteria and ZIF-8 slurry during photocatalytic treatment was collected, centrifuged, and washed with $0.9 \%(\mathrm{w} / \mathrm{v})$ saline solution, followed by staining with dyes of LIVE/ DEAD BBcellProbe ${ }^{\mathrm{TM}}$ N01/PI (BestBio Inc., China) bacterial viability kit according to the manufacturer's protocol. The experiment was carried out using a mixture of 
N01 dye and propidium iodide (PI) dye. Bacterial cells with intact cell membrane (live) are stained by N01 and fluorescent green, whereas PI penetrates only damaged membranes and stains the dead bacterial cells. After incubation in dark for $15 \mathrm{~min}$, the stained samples were observed by a fluorescence microscope (Olympus, FV1000) with $\times 10$ magnification.

ROS measurements. $\cdot \mathrm{O}_{2}{ }^{-}$steady-state concentration was calculated by measuring the decay of NBT (Sigma, 98\%) using UV-vis spectroscopy. NBT has an absorption peak at $260 \mathrm{~nm}$. The rate constant for $\cdot \mathrm{O}_{2}{ }^{-}$and NBT reaction is $5.9 \times$ $10^{4} \mathrm{M}^{-1} \mathrm{~s}^{-1} 25,57 . \mathrm{H}_{2} \mathrm{O}_{2}$ concentration was measured using a HPA fluorescence probe. A fluorescent $p$-hydroxyphenylacetic acid dimer is formed by the reaction of $\mathrm{H}_{2} \mathrm{O}_{2}$ with HPA using horseradish peroxidase as a catalyst. The amount of the dimer is analyzed using a fluorescence spectrophotometer at the emission wavelength of $410 \mathrm{~nm}$ with the excitation at $310 \mathrm{~nm}$. $\bullet O H$ was determined by the fluorescence method using Cou as a probe molecule. One millimolar Cou and 0.5 $\mathrm{mg} \mathrm{mL}^{-1}$ ZIF-8 were dispersed in $20 \mathrm{~mL}$ aqueous solution. Fluorescence spectra of generated 7-hydroxycoumarin, which could emit fluorescence at $455 \mathrm{~nm}$ when excited at $332 \mathrm{~nm}$, was measured. Samples were collected at different time intervals and filtrated by $0.22 \mu \mathrm{m}$ membrane to exclude the influence of bacteria cells and photocatalysts.

Scavenger quenching experiments. The scavengers used was sodium chromate $(\mathrm{Cr}(\mathrm{VI})), 2.5 \mathrm{mM}$, Sigma, $99.5 \%)$ for electron, superoxide dismutase $\left(400 \mathrm{U} \mathrm{mL}^{-1}\right.$, Sigma, 99\%)) for $\bullet^{-}{ }^{-}$, L-histidine for ${ }^{1} \mathrm{O}_{2}$ (L-His, $2.5 \mathrm{mM}$, Sigma, $99 \%$ ), catalase for $\mathrm{H}_{2} \mathrm{O}_{2}\left(300 \mathrm{U} \mathrm{mL}^{-1}\right.$, Sigma), isopropanol $(2.5 \mathrm{mM}$, Sigma, $99.5 \%)$ for $\bullet \mathrm{OH}$ and sodium oxalate $(2.5 \mathrm{mM}$, Sigma, $99.5 \%)$ for hole. The scavengers were added into the bacteria suspension before illumination. The concentrations of bacteria in solution were measured at different time intervals by using standard spread plating techniques. Each sample was serially diluted and each dilution was plated in triplicate onto nutrient agar and incubated at $37^{\circ} \mathrm{C}$ for $20 \mathrm{~h}$.

\section{Data availability}

The data sets generated during and/or analyzed during the current study are available from the corresponding authors on reasonable request. The data behind Figs. 2-5 are available in the Supplementary source data file.

Received: 10 December 2018 Accepted: 12 April 2019

Published online: 16 May 2019

\section{References}

1. Heft-Neal, S., Burney, J., Bendavid, E. \& Burke, M. Robust relationship between air quality and infant mortality in Africa. Nature 559, 254-258 (2018).

2. Lelieveld, J., Evans, J. S., Fnais, M., Giannadaki, D. \& Pozzer, A. The contribution of outdoor air pollution sources to premature mortality on a global scale. Nature 525, 367-317 (2015)

3. Watson, T. Environment: breathing trouble. Nature 513, S14-S15 (2014).

4. Cohen, A. J. et al. Estimates and 25-year trends of the global burden of disease attributable to ambient air pollution: an analysis of data from the Global Burden of Diseases Study 2015. Lancet 389, 1907-1918 (2017).

5. Nelson, H. S. et al. Recommendations for the use of residential air-cleaning devices in the treatment of allergic respiratory diseases. J. Allergy Clin. Immunol. 82, 661-669 (1988).

6. Barn, P. et al. Infiltration of forest fire and residential wood smoke: an evaluation of air cleaner effectiveness. J. Expo. Sci. Environ. Epidemiol. 18, 503-511 (2008).

7. Hinds, W. C. Aerosol Technology: properties, behavior, and measurement of airborne particles. J. Aerosol Sci. 31, 1121-1122 (2000).

8. Liu, C. et al. Transparent air filter for high-efficiency PM2.5 capture. Nat. Commun. 6, 6205-6214 (2015)

9. Batterman, S., Godwin, C. \& Jia, C. Long duration tests of room air filters in cigarette smokers' homes. Environ. Sci. Technol. 39, 7260-7268 (2005).

10. Zhang, $X$. et al. High-performance inertial impaction filters for particulate matter removal. Sci. Rep. 8, 4757-4764 (2018).

11. Chuaybamroong, P. et al. Efficacy of photocatalytic HEPA filter on microorganism removal. Indoor Air 20, 246-254 (2010).

12. Korves, T. M. et al. Bacterial communities in commercial aircraft highefficiency particulate air (HEPA) filters assessed by PhyloChip analysis. Indoor Air 23, 50-61 (2013).

13. Simmons, R. B., Price, D. L., Noble, J. A., Crow, S. A. \& Ahearn, D. G. Fungal colonization of air filters from hospitals. Am. Ind. Hyg. Assoc. J. 58, 900-904 (1997).

14. McDonald, B. C. et al. Volatile chemical products emerging as largest petrochemical source of urban organic emissions. Science 359, 760-764 (2018).
15. Wallace, L. Indoor particles: a review. J. Air Waste Manag. Assoc. 46, 98-126 (1996).

16. Hubbard, H., Poppendieck, D. \& Corsi, R. L. Chlorine dioxide reactions with indoor materials during building disinfection: surface uptake. Environ. Sci. Technol. 43, 1329-1335 (2009).

17. Chen, F., Yang, X., Mak, H. K. C. \& Chan, D. W. T. Photocatalytic oxidation for antimicrobial control in built environment: a brief literature overview. Build. Environ. 45, 1747-1754 (2010).

18. Grinshpun, S. A. et al. Control of aerosol contaminants in indoor air: combining the particle concentration reduction with microbial inactivation. Environ. Sci. Technol. 41, 606-612 (2007).

19. Johnson, M. L., Berger, L., Philips, L. \& Speare, R. Fungicidal effects of chemical disinfectants, UV light, desiccation and heat on the amphibian chytrid Batrachochytrium dendrobatidis. Dis. Aquat. Org. 57, 255-260 (2003).

20. Nazaroff, W. W. \& Weschler, C. J. Cleaning products and air fresheners: exposure to primary and secondary air pollutants. Atmos. Environ. $\mathbf{3 8}$, 2841-2865 (2004)

21. Walker, C. M. \& Ko, G. Effect of ultraviolet germicidal irradiation on viral aerosols. Environ. Sci. Technol. 41, 5460-5465 (2007).

22. Hodges, B. C., Cates, E. L. \& Kim, J.-H. Challenges and prospects of advanced oxidation water treatment processes using catalytic nanomaterials. Nat. Nanotechnol. 13, 642-650 (2018).

23. Wang, H. et al. Semiconductor heterojunction photocatalysts: design, construction, and photocatalytic performances. Chem. Soc. Rev. 43, 5234-5244 (2014).

24. Yu, J. C. et al. Efficient visible-light-induced photocatalytic disinfection on sulfurdoped nanocrystalline titania. Environ. Sci. Technol. 39, 1175-1179 (2005).

25. Liu, C. et al. Rapid water disinfection using vertically aligned $M_{2} S_{2}$ nanofilms and visible light. Nat. Nanotechnol. 11, 1098-1106 (2016).

26. Si, Y. et al. Daylight-driven rechargeable antibacterial and antiviral nanofibrous membranes for bioprotective applications. Sci. Adv. 4, 5931-5942 (2018).

27. Nosaka, Y. \& Nosaka, A. Y. Generation and detection of reactive oxygen species in photocatalysis. Chem. Rev. 117, 11302-11336 (2017).

28. Jacoby, W. A., Maness, P. C., Wolfrum, E. J., Blake, D. M. \& Fennell, J. A. Mineralization of bacterial cell mass on a photocatalytic surface in air. Environ. Sci. Technol. 32, 2650-2653 (1998).

29. Furukawa, H., Cordova, K. E., O'Keeffe, M. \& Yaghi, O. M. The chemistry and applications of metal-organic frameworks. Science 341, 974-982 (2013).

30. DeCoste, J. B. \& Peterson, G. W. Metal-organic frameworks for air purification of toxic chemicals. Chem. Rev. 114, 5695-5727 (2014).

31. Barea, E., Montoro, C. \& Navarro, J. A. R. Toxic gas removal metal-organic frameworks for the capture and degradation of toxic gases and vapours. Chem. Soc. Rev. 43, 5419-5430 (2014).

32. Wang, H. et al. An iron-containing metal-organic framework as a highly efficient catalyst for ozone decomposition. Angew. Chem. Int. Ed. https://doi. org/10.1002/ange.201810268 (2018)

33. Zhang, Y. et al. Preparation of nanofibrous metal-organic framework filters for efficient air pollution control. J. Am. Chem. Soc. 138, 5785-5788 (2016)

34. Chen, Y. et al. Roll-to-roll production of metal-organic framework coatings for particulate matter removal. Adv. Mater. 29, 1606221-1606227 (2017).

35. Zhang, T. \& Lin, W. Metal-organic frameworks for artificial photosynthesis and photocatalysis. Chem. Soc. Rev. 43, 5982-5993 (2014).

36. Fang, Y. et al. Metal-organic frameworks for solar energy conversion by photoredox catalysis. Coord. Chem. Rev. 373, 83-115 (2018).

37. $\mathrm{Lu}, \mathrm{W}$. et al. Tuning the structure and function of metal-organic frameworks via linker design. Chem. Soc. Rev. 43, 5561-5593 (2014).

38. Zhang, H. et al. Engineering coordination polymers for photocatalysis. Nano Energy 22, 149-168 (2016).

39. $\mathrm{Xu}, \mathrm{H}$. Q. et al. Visible-light photoreduction of $\mathrm{CO}_{2}$ in a metal-organic framework: boosting electron-hole separation via electron trap states. J. Am. Chem. Soc. 137, 13440-13443 (2015).

40. Liu, Y., Howarth, A. J., Hupp, J. T. \& Farha, O. K. Selective photooxidation of a mustard-gas simulant catalyzed by a porphyrinic metal-organic framework. Angew. Chem. Int. Ed. 54, 9001-9005 (2015).

41. Dhakshinamoorthy, A., Li, Z. \& Garcia, H. Catalysis and photocatalysis by metal organic frameworks. Chem. Soc. Rev. 47, 8134-8172 (2018).

42. Li, Y., Niu, J., Zhang, W., Zhang, L. \& Shang, E. Influence of aqueous media on the ROS-mediated toxicity of $\mathrm{ZnO}$ nanoparticles toward green fluorescent protein-expressing Escherichia coli under UV-365 irradiation. Langmuir 30, 2852-2862 (2014)

43. Đolić, M. B. et al. Natural sorbents modified by divalent $\mathrm{Cu}^{2+}$ - and $\mathrm{Zn}^{2+}$-ions and their corresponding antimicrobial activity. N. Biotechnol. 39, 150-159 (2017).

44. Ng, A. M. et al. Antibacterial and photocatalytic activity of $\mathrm{TiO}_{2}$ and $\mathrm{ZnO}$ nanomaterials in phosphate buffer and saline solution. Appl. Microbiol. Biotechnol. 97, 5565-5573 (2013).

45. Liu, J. et al. The active roles of ZIF-8 on the enhanced visible photocatalytic activity of $\mathrm{Ag} / \mathrm{AgCl}$ : Generation of superoxide radical and adsorption. J. Alloy. Compd. 693, 543-549 (2017). 
46. Qi, G. et al. Low-temperature reactivity of $\mathrm{Zn}^{+}$ions confined in ZSM-5 zeolite toward carbon monoxide oxidation: insight from in situ DRIFT and ESR spectroscopy. J. Am. Chem. Soc. 135, 6762-6765 (2013).

47. Wardman, P. Reduction potentials of one-electron couples involving free radicals in aqueous solution. J. Phys. Chem. Ref. Data 18, 1637-1755 (1989).

48. Bielski, B. H. J., Cabelli, D. E., Arudi, R. L. \& Ross, A. B. ChemInform abstract: reactivity of perhydroxyl/superoxide radicals in aqueous solution. J. Phys. Chem. Ref. Data 14, 1041-1100 (1985).

49. Ishibashi, K.-i., Fujishima, A., Watanabe, T. \& Hashimoto, K. Detection of active oxidative species in $\mathrm{TiO}_{2}$ photocatalysis using the fluorescence technique. Electrochem. Commun. 2, 207-210 (2000).

50. Bielski, B. H. J., Cabelli, D. E., Arudi, R. L. \& Ross, A. B. Reactivity of $\mathrm{HO}_{2} / \mathrm{O}^{-}$ radicals in aqueous solution. J. Phys. Chem. Ref. Data 14, 1041-1100 (1985).

51. Chen, Y. et al. A solvent-free hot-pressing method for preparing metal-organicframework coatings. Angew. Chem. Int. Ed. 55, 3419-3423 (2016).

52. Wang, L. et al. Fe/Ni metal-organic frameworks and their binder-free thin films for efficient oxygen evolution with low overpotential. ACS Appl. Mater. Interfaces 8, 16736-16743 (2016).

53. Hu, S. et al. Effects of monocarboxylic acid additives on synthesizing metalorganic framework nh2-mil-125 with controllable size and morphology. Cryst. Growth Des. 17, 6586-6595 (2017).

54. Katz, M. J. et al. A facile synthesis of UiO-66, UiO-67 and their derivatives. Chem. Commun. 49, 9449-9451 (2013).

55. Park, K. S. et al. Exceptional chemical and thermal stability of zeolitic imidazolate frameworks. Proc. Natl Acad. Sci. USA 103, 10186-10191 (2006).

56. Cravillon, J. et al. Controlling zeolitic imidazolate framework nano- and microcrystal formation: insight into crystal growth by time-resolved in situ static light scattering. Chem. Mater. 23, 2130-2141 (2011).

57. Blelski, B. H. J., Shiue, G. G. \& Bajuk, S. Reduction of nitro blue tetrazolium by COP- and 02-radicals. J. Phys. Chem. 84, 830-833 (1980).

\section{Acknowledgements}

This work was financially supported by the National Natural Science Foundation of China (Grant Nos. 2165102, 21471018, 21490570, 21674012, 21801017), Beijing Municipal Science and Technology Project (Z181100004418001), Beijing Natural Science Foundation (2184121), and Beijing Institute of Technology Research Fund Program

\section{Author contributions}

P.L. synthesized the catalysts and conducted all the structure analysis and the photocatalytic studies. J.Z.L., X.F., J.L., Y.C.H., J.W.Z., H.W., A.X.Y. and J.W.Z. assisted with the material characterizations and catalysis measurements. B.W. and X.J.M. co-wrote the paper. B.W. and X.J.M. supervised the research. All authors discussed the results and assisted during manuscript preparation.

\section{Additional information}

Supplementary Information accompanies this paper at https://doi.org/10.1038/s41467019-10218-9.

Competing interests: The authors declare no competing interests.

Reprints and permission information is available online at http://npg.nature.com/ reprintsandpermissions/

Journal peer review information: Nature Communications thanks the anonymous reviewers for their contribution to the peer review of this work. Peer reviewer reports are available.

Publisher's note: Springer Nature remains neutral with regard to jurisdictional claims in published maps and institutional affiliations.

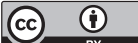

Open Access This article is licensed under a Creative Commons Attribution 4.0 International License, which permits use, sharing, adaptation, distribution and reproduction in any medium or format, as long as you give appropriate credit to the original author(s) and the source, provide a link to the Creative Commons license, and indicate if changes were made. The images or other third party material in this article are included in the article's Creative Commons license, unless indicated otherwise in a credit line to the material. If material is not included in the article's Creative Commons license and your intended use is not permitted by statutory regulation or exceeds the permitted use, you will need to obtain permission directly from the copyright holder. To view a copy of this license, visit http://creativecommons.org/ licenses/by/4.0/.

(C) The Author(s) 2019 